\title{
STABILITY OF AMORPHOUS CALCIUM PHOSPHATE ADSORBED GLYCINE IN RINGER SOLUTION
}

\author{
YOSHIYUKI KOJIMA, TAMOTSU YASUE and YASUO ARAI
}

Department of Industrial chemistry, Faculty of science and Engineering, Nihon University, 1-8, Kanda-Surugadai, Chiyoda-ku, Tokyo 101, Japan

\begin{abstract}
Study was made to investigate stability of amorphous calcium phosphate (ACP) adsorbed glycine in ringer solution having a composition similar to the body fluid in vivo and in ringer solution including glycine. Characterization of the products was determined by means of X-ray diffraction, thermal analysis (TG-DTA) and ion chromatography. $\mathrm{pH}$ in suspension which was dipped ACP adsorbed glycine in ringer solution of initial $\mathrm{pH}$ of 7.3 at $35^{\circ} \mathrm{C}$ was reached to 7.2 for 12 hours. Then stability of ACP adsorbed glycine was decreased as a result of deadsorption of glycine adsorbent and crystallization of ACP to hydroxyapatite (HAp). The glycine adsorbent of $1.4 \mathrm{wt} \%$ was adsorbed about $7.3 \mathrm{wt} \%$ on HAp crystallized in ringer solution including glycine. The largest quantity of glycine on ACP was increased to $13.3 \mathrm{wt} \%$ in ringer solution including glycine. HAp formed from ACP adsorbed glycine as starting sample was able to control thickness of capsulation film by adhesion of cell in vivo.
\end{abstract}

\section{INTRODUCTION}

Calcium phosphate was major component of inorganic materials such as bone and teeth in vivo. In the case of using calcium phosphate as biomaterials, its biocompatibility and conformability in vivo were better than those of other materials such as metal, polymer and ceramics. The most of calcium phosphate which was formed composites with collagen as one of hard protein was hydroxyapatite $\left(\mathrm{Ca}_{10}\left(\mathrm{PO}_{4}\right)_{6}(\mathrm{OH})_{2}, \mathrm{HAp}\right)$. Under biological conditions, amorphous calcium phosphate (ACP) was generally known to form during the initial stage of HAp synthesis and was eventually transformed to low crystalline HAp. ${ }^{1}$ ACP having property of fine and high activity was to be expect promotion effect such as adsorption of organic compound and formation of composites with collagen. The authors were investigated a series to propose appearance of new functionally of ACP compounds. ${ }^{2-4}$ The glycine as amino acid consisting collagen as one of fibrous protein was reported adsorbing to ACP in previous paper. 4 Therefore, amount of glycine adsorbed on ACP was controlled by changing synthetic conditions such as concentration of glycine, initial $\mathrm{pH}$, temperature 
and aging time. The biocompatibility for biomaterials was regarded as major importance. The implant material with non-biocompatibility in vivo was increased thickness of capsulation film by adhesion of cell and did not suit for biomaterials. ${ }^{5}$ The present study was made to investigate stability of ACP adsorbed glycine in ringer solution having a composition similar to body fluid in vivo.

\section{EXPERIMENTAL}

\section{MATERIALS}

The reagents used for the synthesis of ACP adsorbed glycine were anhydrous calcium chloride $\left(\mathrm{CaCl}_{2}\right)$, dipotassium hydrogenphosphate $\left(\mathrm{K}_{2} \mathrm{HPO}_{4}\right)$, potassium hydroxide $(\mathrm{KOH})$ and glycine $\left(\mathrm{C}_{2} \mathrm{H}_{5} \mathrm{O}_{2} \mathrm{~N}\right)$ as amino acid, all supplied by Kanto Chemical Co.Ltd. In addition, reagent grade HAp (100 to 200 meshes) for column chromatography supplied by Nakaraitesuku Co.Ltd. was also used for comparison. The compositions of ringer solution were $\mathrm{NaCl} 0.85 \mathrm{wt} \%, \mathrm{KCl} 0.02 \mathrm{wt} \%$, $\mathrm{CaCl}_{2} 0.02 \mathrm{wt} \%$ and $\mathrm{NaHCO}_{3} 0.002 \mathrm{wt} \%$.

\section{EXPERIMENTAL METHOD}

$\mathrm{ACP}$ adsorbed glycine was synthesized by rapidly adding $\mathrm{CaCl}_{2}$ solution $(0.167 \mathrm{~mol}$ $\left.\mathrm{dm}^{-3}\right)$ into $\mathrm{K}_{2} \mathrm{HPO}_{4}$ solution $\left(0.100 \mathrm{~mol} \mathrm{dm}^{-3}\right)$. In advance, the $\mathrm{K}_{2} \mathrm{HPO}_{4}$ solution was added with powdered glycine $(0 \sim 15 \mathrm{wt} \%)$ and with the $\mathrm{KOH}$ solution to control $\mathrm{pH}$ during the synthesis process. Volume of the $\mathrm{CaCl}_{2}$ solution was set to the same as that of $\mathrm{K}_{2} \mathrm{HPO}_{4}$ solution and reaction temperature was held at $0^{\circ} \mathrm{C}$. Gelatinous ACP adsorbed glycine was immediately formed after the reaction, was aged in the mother liquor at $0 \sim 40^{\circ} \mathrm{C}$ for $0 \sim 24$ hours, and then was filtered by a glass filter (G5). The gel was washed with $\mathrm{KOH}$ solution kept at the same $\mathrm{pH}$ as that used for the synthesis and acetone, treated with silica gel to remove moisture and finally dried in air to prepare ACP adsorbed glycine. The stability of ACP was studied by dipping in ringer solution having a composition similar to the body fluid in vivo and in ringer solution including glycine. Characterization of the products was determined by means of $\mathrm{X}$ ray diffraction, thermal analysis ( TG-DTA) and ion chromatography. The compositions of products were determined quantity of calcium by chemical analysis, and quantities of phosphorus and glycine adsorbed on the products by ion chromatography.

\section{RESULTS AND DISCUSSION}

The preparation of the biomaterials for implant materials has to consider interface suitability between vital surface and material surface as conformability. 
Under biological conditions, the adsorption of protein onto material was valuated by adsorbing glycine on ACP in ringer solution.

Figure 1 illustrates change in $\mathrm{pH}$ of suspension by dipping ACP adsorbed glycine of $1.4 \mathrm{wt} \%$ in ringer solution at $35^{\circ} \mathrm{C}$. In ringer solution of initial $\mathrm{pH}$ of 7.3 , the $\mathrm{pH}$ was risen to 8.0 for 1 hour and then was equilibrated at 7.2 for 12 hours. When ACP was dipped in ringer solution, $\mathrm{pH}$ was tended slightly decreasing compared with the result of the glycine adsorbent. In ringer solution including glycine of initial $\mathrm{pH}$ of 6.1 , the $\mathrm{pH}$ was slowly risen and was reached to 6.6 for 24 hours. As a result of X-ray diffraction of the crystallization process of ACP to HAp, ACP dipped in ringer solution was held amorphous state till 1 hour and then was crystallized to HAp above 1 hour. However, ACP dipped in ringer solution including glycine was quickly crystallized to HAp.

Figure 2 illustrates amount of glycine adsorbed on HAp crystallized by dipping ACP or ACP adsorbed glycine in ringer solution including glycine. Amount of glycine adsorbed on HAp which was obtained by dipping glycine adsorbent of $1.4 \mathrm{wt} \%$ in the ringer solution was increased till 3 hours and the largest quantity of glycine adsorbed on HAp was approximately $8.2 w t \%$. Then amount of glycine after 24 hours was decreased to $7.3 w t \%$ to deadsorb glycine. On the other hands, the largest quantity of ACP was $16 w t \%$ for 3 hours and then was constant with $13.3 \mathrm{wt} \%$. However, in the case of dipping each $\mathrm{ACP}$ in ringer

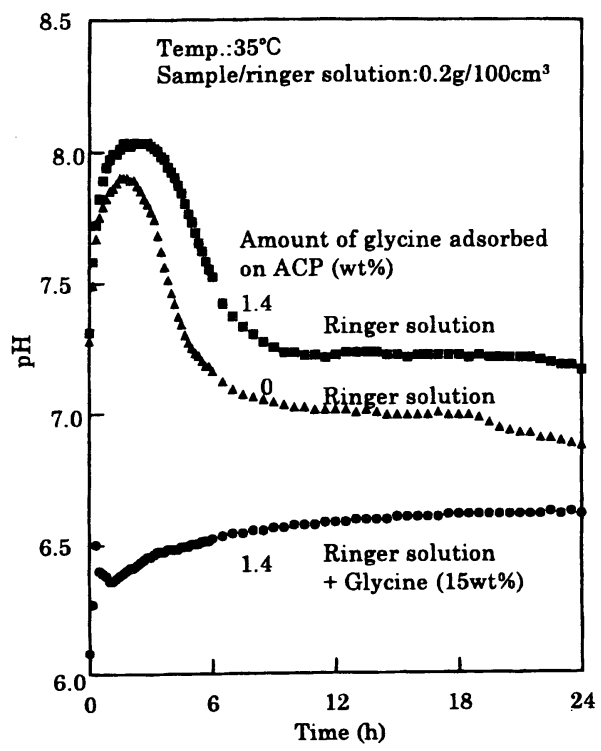

Figure 1. Change in $\mathrm{pH}$ by dipping $\mathrm{ACP}$ adsorbed glycine in ringer solution.

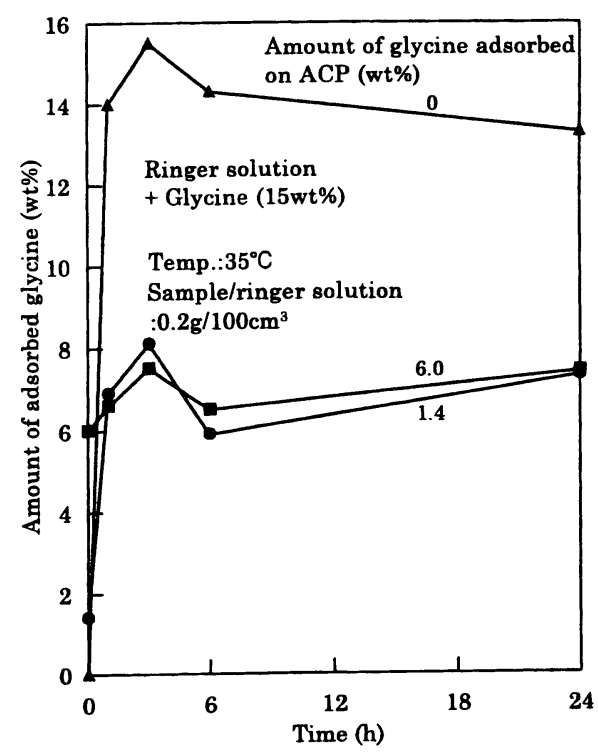

Figure 2. Change in amount of adsorbed glycine by dipping ACP adsoerbed glycine in ringer solution. 
solution, adsorption of glycine on HAp was almost found. Further, reagent grade HAp dipped in glycine solution was almost adsorbed. The specific surface area of HAp crystallized from ACP was larger than that of HAp formed from ACP adsorbed glycine. Namely, particle size of crystallized HAp was affected by amount of glycine adsorbed on ACP. The excess glycine adsorbed on HAp under biological conditions was undesirable to increase thickness capsulation film by adhesion of cell in vivo.

Figure 3 illustrates relationship between amount of glycine adsorbed on HAp and ACP. It was became apparent that ACP was crystallized to HAp which was adsorbed glycine of $13.3 \mathrm{wt} \%$. ACP adsorbed glycine of $1.4 \mathrm{wt} \%$ was crystallized to HAp which was adsorbed glycine of $7.3 w t \%$ and ACP adsorbed glycine of $4.0 w t \%$ was adsorbed about $7.2 \mathrm{wt} \%$. Namely, amount of glycine adsorbed on ACP as starting sample was not hardly

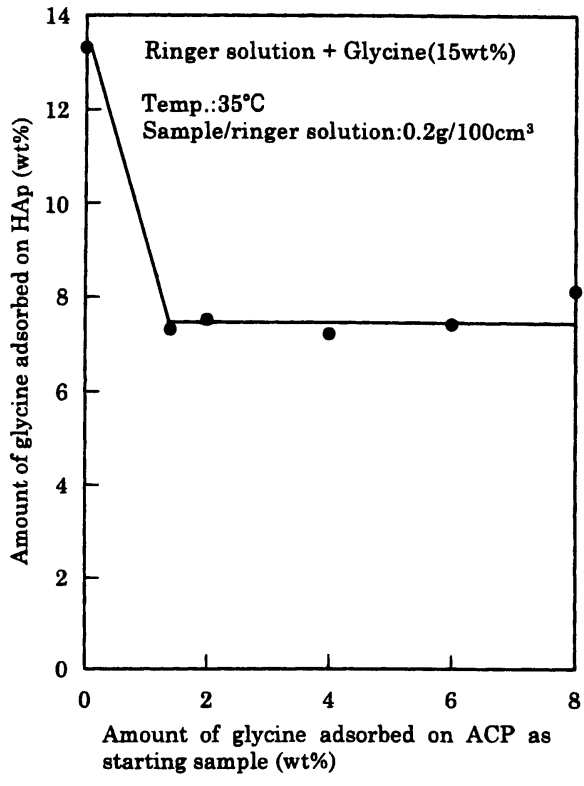

Figure 3. Relationship between amount of glycine readsorbed on HAp and adsorbed on ACP.

affected to that of HAp. HAp formed from ACP adsorbed glycine was able to restrain thickness of capsulation film by adhesion of cell in vivo.

DTA curve of HAp adsorbed glycine of $13.3 \mathrm{wt} \%$ obtained from ACP was found endothermic peak at $305{ }^{\circ} \mathrm{C}$ due to decomposition of adsorbed glycine. However, HAp adsorbed glycine of $8.0 \mathrm{wt} \%$ obtained from ACP adsorbed glycine was found endothermic peak at $355^{\circ} \mathrm{C}$ and was strongly adsorbed glycine on HAp.

\section{REFERENCES}

1) T.Yasue and Y.Arai,Sekko to Sekkai, No.243,42(1993).

2) T.Yasue,K.Masuda,Y.Kojima and Y.Arai,J.Ceram.Soc.Jpn.,102, 1122(1994).

3) Y.Kojima,K.Sakama,T.Toyama,T.Yasue and Y.Arai, Phosph.Res.Bull.4 474(1994).

4) Y.Kojima,Y.Yamamoto,T.Yasue and Y.Arai,Phosph.Res.Bull., $\underline{\mathbf{5}}, 59(1995)$.

5) Y.Ikada, "Biomaterials" ,Nikkan Kogyo(1983)p.218. 